Article

\title{
Pozzolanic Reactivity of Silica Fume and Ground Rice Husk Ash as Reactive Silica in a Cementitious System: A Comparative Study
}

\author{
Weiting $\mathrm{Xu}{ }^{1, *}$, Tommy Yiu Lo ${ }^{2}$, Weilun Wang ${ }^{1, *}$, Dong Ouyang ${ }^{3}$, Penggang Wang ${ }^{4}$ \\ and Feng Xing ${ }^{1}$ \\ 1 Guangdong Provincial Key Laboratory of Durability for Marine Civil Engineering, College of Civil \\ Engineering, Shenzhen University, Shenzhen 518060, China; xingf@szu.edu.cn \\ 2 Department of Architectural and Civil Engineering, City University of Hong Kong, Hong Kong, China; \\ bctommyl@cityu.edu.hk \\ 3 Department of Mechanics and Civil Engineering, College of Science and Engineering, Jinan University, \\ Guangzhou 510632, China; toud@jnu.edu.cn \\ 4 Ceneter for Durability and Sustainability Studies of Shandong Province, Qingdao Uiniversity of Technology, \\ Qingdao 266033, China; wangpenggang007@gmail.com \\ * Correspondence: weitinxu@gmail.com (W.X.); wwl0610@szu.edu.cn (W.W.); \\ Tel.: +86-755-2601-3871 (W.X. \& W.W.); Fax: +86-755-2653-4021 (W.X. \& W.W.)
}

Academic Editor: Jorge de Brito

Received: 10 November 2015; Accepted: 17 February 2016; Published: 1 March 2016

\begin{abstract}
This study comparably assessed the pozzolanic effect of silica fume (SF) and ground rice husk ash (RHA) as supplementary cementing materials on the properties of blended cement pastes and concretes. A commonly commercial silica fume (SF) and locally-produced rice husk ash (RHA) samples with two finenesses (one with larger size than cement and the other with smaller size than cement) were used in this study. Material properties of SF and RHA were experimentally characterized. Hydration and mechanical properties of cement pastes incorporating SF and RHA were determined by thermogravimetric analysis (TGA) and compressive strength tests, respectively. Properties of concretes regarding workability, mechanical property, durability, and microstructure were evaluated. Results showed that, although the finely ground RHA used in this study possessed lower $\mathrm{SiO}_{2}$ content and higher particle size compared to SF, it exhibited comparable pozzolanic reactivity with SF due to the nano-scale pores on its each single particle, leading to a higher specific surface area. The optimal replacement levels of SF and RHA were $10 \%$ by weight of cement in pastes and concretes. Although addition of SF and RHA led to a significant reduction in slump for the fresh mixtures, inclusion of up to $30 \%$ of SF or 15\% of ground RHA did not adversely affect the strength of concretes. At the same mix, incorporation of finely-ground RHA in cement composites provided comparable mechanical properties, hydration degree, and durability with SF blended cement composites, owing to the porous structure and high specific surface area of RHA particles. Microstructure morphology analysis of concretes explored by scanning electron microscopy (SEM) further validated the strength and the durability test results.
\end{abstract}

Keywords: silica fume; rice husk ash; pozzolanic reactivity; strength; chloride ion penetration resistance; morphology

\section{Introduction}

In the manufacture of cement, the clinker production process requires a great amount of energy and emits a large amount of carbon dioxide $\left(\mathrm{CO}_{2}\right)$ into the atmosphere. The increase in $\mathrm{CO}_{2}$ emissions 
has led to the greenhouse effect and an increase in the temperature of the Earth. To reduce the environmental problems, industrial and agricultural byproducts such as fly ash, metakaolin, granulated blast furnace slag, etc., have been used as supplementary cementing materials to reduce the production of cement, thus reducing the emission of $\mathrm{CO}_{2}$ and the use of energy [1-7]. Moreover, the incorporation of these cement replacement materials in concretes has been reported to improve the mechanical properties and penetration resistance of the concretes [8-13].

Silica fume (SF) and rice hush ash (RHA) are both siliceous materials. They are highly concentrated sources of amorphous $\mathrm{SiO}_{2}$ and possess similar chemical reaction mechanism in cement matrix system. The reactivity of SF and RHA contributes to the strength enhancement of cement-basted materials by pozzolanic reactions between amorphous silica and calcium hydroxide liberated during the cement hydration process. These reactions produce additional amounts of C-S-H gel that makes denser microstructure of SF and RHA containing cement-based materials [14,15].

SF is very fine non-crystalline silica produced by an electric arc furnace as a byproduct of the smelting process in the production of metallic silicon or ferrosilicon in the alloys industry. The reduction of high-purity quartz to silicon at temperatures up to $2000{ }^{\circ} \mathrm{C}$ produces $\mathrm{SiO}_{2}$ vapors, which oxidize and condense in the low-temperature zone to tiny particles consisting of $85 \%-99 \%$ amorphous silica [16]. Then, SF is composed of submicron particles of silicon dioxide, which occur as almost-perfect spheres with diameters ranging from 20 to $500 \mathrm{~nm}$ [17]. It is estimated that current global output of SF is, at most, between one and 1.5 million tonnes per year [18]. It has been widely reported that higher strength and durability enhancement can be obtained for concretes containing silica fume. Performance of silica fume concretes in sulfate environment is also better than normal Portland cement concretes [19-21].

RHA is the combustion residue of the rice husks, which are the shells produced during the dehusking operation of paddy rice. Each tonne of paddy rice produces about $200 \mathrm{~kg}$ of husk which, on combustion, yield approximately $40 \mathrm{~kg}$ ash. Rice plants ingest orthosilicic acid from groundwater, whereupon it is polymerized to form amorphous silica in the husks [22]. After combustion, the organic compounds are devolatilized as carbon dioxide, while the silica is retained in the ash residue. Studies have shown that the main chemical composition of RHA is biomass silicon dioxide $\left(\mathrm{SiO}_{2}\right)$, and processing conditions have a significant effect on the characteristics of silica in RHA. The ash formed during open-field burning or uncontrolled combustion in furnaces generally contains a large proportion of less reactive crystalline silica minerals such as cristobalite and tridymite. The highest amount of amorphous silica is achieved when RHA is burned between 500 and $700{ }^{\circ} \mathrm{C}$ [23]. Reactivity of RHA is attributed to its high content of amorphous silica and its very large surface area governed by the porous structure of the particles [24]. Generally, the reactivity is also favored by increasing the fineness of the ash [25]. As a pozzolanic material, RHA can be used to replace Portland cement by up to $15 \%$ [26]. RHA with high fineness can improve the compressive strength and produce mortars with low porosity. For durability, the use of RHA significantly improves resistance to water permeability, chloride ion penetration, and sulfate deterioration of concretes [27-29].

To date, intensive research efforts have been made in optimal cement replacement level and enhancement of blended concretes for SF dust and RHA. It has been widely accepted that SF and RHA as super pozzolans can significantly improve various properties of concretes. However, it is not aware of any literature wherein a systematically comparative study on pozzolanic reactivity of SF and ground RHA as reactive silica in cementitious system. Moreover, one of the main dimensions of this investigation was to explore the feasibility of RHA instead of SF (which is not economically available even in developed countries) in mortars and concretes. This would also reduce the environmental problems associated with the current open field burning of the rice husk. Therefore, efforts may be made to encourage the use of RHA in construction materials.

This paper launches a comparative study to assess the pozzolanic reactivity of SF and RHA. The hydration properties of cement pastes incorporating SF and RHA after the compressive strength test were determined by thermogravimetric analysis. Properties regarding workability and mechanical properties of concretes were monitored by slump test, compressive strength test, and splitting tensile 
strength test. The durabilities of concretes were evaluated by rapid chloride iron penetration testing. The microstructures of concretes were explored through scanning electron microscopy (SEM) analysis.

\section{Experimental}

\subsection{Constituent Materials of Blended Cement Pastes and Concretes}

An ordinary Portland cement provided from Green Island Cement Co Ltd (Hong Kong) CEM II 52.5 complying with BS12 [30] standard was used. The cement had a specific gravity of 3.12 and the fineness of $0.34 \mathrm{~m}^{2} / \mathrm{g}$.

A commonly commercial silica fume used in this study was supplied from Xilong Chemical Co., Ltd. (Shantou, China).

Locally-produced RHA samples were obtained by burning rice husk at a specified temperature of $600{ }^{\circ} \mathrm{C}$ for two hours at a heating rate of $20^{\circ} \mathrm{C} / \mathrm{min}$ in an electronic furnace. For the grinding process, a laboratory stainless ball mill manufactured by Nanjing University, Nanjing, China, was used to grind the raw ash to smaller particles. The rotational milling speed was set as $1000 \mathrm{RPM}$, and the mass ratio with ball to powder was 20:1. The grinding duration was set as 5 and $30 \mathrm{~min}$, respectively. After each grinding intermission the ground sample was taken out to keep in a dry sealed container for subsequent tests.

River sand with a fineness modulus of 2.44 and specific gravity of 2.65 was used as the fine aggregate. Crushed granites with two size ranges $(20$ and $40 \mathrm{~mm})$ and having specific gravity of 2.67 were used as the coarse aggregate.

A naphthalene-based superplasticizer, Daracem ${ }^{\circledR} 108$, Grace Construction Products, Hong Kong, produced in liquid form was used.

\subsection{Characterization of Constituent Materials}

The chemical compositions of constituent materials were monitored by X-ray fluorescence (XRF). Mineralogical analyses were performed by X-ray diffractometry (XRD), using a Phillips PW 1050 diffractometer (Philips, Belgrade, Serbia) with a 50 kV, $50 \mathrm{~mA} \mathrm{Cu}$ radiation source. Particle morphologies were taken by environmental scanning electron microscope (ESEM) (FEI XL30 S-FEG, FEI Co., Hillsboro, OR, USA) with a $20 \mathrm{kV}$ accelerating voltage. Mean particle sizes were monitored by a laser particle size analyzer (Microtrac SR150, Microtrac Inc., Dallas, TX, USA). Specific gravities were measured according to ASTM D5550-14 [31]. Specific surface areas were determined by the Blain method for cement and nitrogen adsorption analysis for SF and RHA.

\subsection{Preparation and Testing of Blended Cement Pastes}

SF and RHA blended cements were prepared by replacing $10 \%$ of cement weight by ground RHAs and SF in a dry condition. The mixtures were thoroughly homogenized and kept in sealed bags. The blended cement pastes were prepared with a water to binder ratio of 0.4 at room temperature of $20 \pm 2{ }^{\circ} \mathrm{C}$. All of the fresh paste mixtures were cast into $20 \mathrm{~mm} \times 20 \mathrm{~mm} \times 20 \mathrm{~mm}$ cube molds. After $24 \mathrm{~h}$, the pastes were demolded and cured at $20^{\circ} \mathrm{C}$ with $\mathrm{RH}$ higher than $95 \%$ until the day for the subsequent tests.

As for the compressive strength tests, all the cementitious pastes were tested at $1,3,7,28$, and 90 days in accordance with ASTM C109 standard [32].

In order to study the hydration reaction of the cementitious pastes, the paste specimens were ground to obtain homogeneity of the grain size below 50 microns and subjected to the quantitative thermogravimetric analysis (TGA). The TGA heating temperature range was run at $50-900{ }^{\circ} \mathrm{C}$ and with a heating rate of $10^{\circ} \mathrm{C}$ per minute. The TGA curves were plotted and the weight losses of the pastes at $1,3,7$, and 28 days were calculated. As the different chemical compounds in cement correspond to certain decomposition weight losses of TGA curves, the qualitative evaluation of the hydration degree of pastes can be assessed [33]. 


\subsection{Mix Proportions of Concretes}

Concrete mix proportions were listed in Table 1. 13 concrete mix proportions were prepared with the same amount of binder $\left(560 \mathrm{~kg} / \mathrm{m}^{3}\right)$ and water to binder ratio $(\mathrm{w} / \mathrm{b})$ of 0.3 .

Table 1. Mix proportions of the concrete specimens.

\begin{tabular}{ccccccccc}
\hline \multirow{2}{*}{$\begin{array}{c}\text { Concrete } \\
\text { ID }\end{array}$} & $\mathbf{w} / \mathbf{b}$ & Cement & SF & FRHA & Sand & Granite & Course Granite & S.P. \\
\cline { 2 - 8 } & - & $\mathbf{k g} / \mathbf{m}^{\mathbf{3}}$ & $\mathbf{k g} / \mathbf{m}^{\mathbf{3}}$ & $\mathbf{k g} / \mathbf{m}^{\mathbf{3}}$ & $\mathbf{k g} / \mathbf{m}^{\mathbf{3}}$ & $\mathbf{k g} / \mathbf{m}^{\mathbf{3}}$ & $\mathbf{k g} / \mathbf{m}^{\mathbf{3}}$ & $\mathbf{k g} \mathbf{m}^{\mathbf{3}}$ \\
\hline Control & 0.3 & 560 & - & - & 725 & 305 & 695 & 9.02 \\
SF5\%C & 0.3 & 532 & 28 & 0 & 725 & 305 & 695 & 9.02 \\
SF10\%C & 0.3 & 504 & 56 & 0 & 725 & 305 & 695 & 9.02 \\
SF15\%C & 0.3 & 476 & 84 & 0 & 725 & 305 & 695 & 9.02 \\
SF20\%C & 0.3 & 448 & 112 & 0 & 725 & 305 & 695 & 9.02 \\
SF25\%C & 0.3 & 420 & 140 & 0 & 725 & 305 & 695 & 9.02 \\
SF30\%C & 0.3 & 392 & 168 & 0 & 725 & 305 & 695 & 9.02 \\
FRHA5\%C & 0.3 & 532 & 0 & 28 & 725 & 305 & 695 & 9.02 \\
FRHA10\%C & 0.3 & 504 & 0 & 56 & 725 & 305 & 695 & 9.02 \\
FRHA15\%C & 0.3 & 476 & 0 & 84 & 725 & 305 & 695 & 9.02 \\
FRHA20\%C & 0.3 & 448 & 0 & 112 & 725 & 305 & 695 & 9.02 \\
FRHA25\%C & 0.3 & 420 & 0 & 140 & 725 & 305 & 695 & 9.02 \\
FRHA30\%C & 0.3 & 392 & 0 & 168 & 725 & 305 & 695 & 9.02 \\
\hline
\end{tabular}

Note: S.P.: Superplasticizer.

Cement was partially replaced by SF and finely ground RHA (FRHA) at 5\%, 10\%, 15\%, 20\%, 25\%, and $30 \%$ by mass. The amounts of superplasticizer in all concrete mixtures were adjusted in order to control the slump of fresh control concrete between 60 and $90 \mathrm{~mm}$.

\subsection{Preparation and Testing of Concretes}

The effects of SF and ground RHA on the workability of concrete were determined by comparing slump values of fresh concretes.

The compressive strength test was carried out in concrete cubes of size $100 \mathrm{~mm} \times 100 \mathrm{~mm} \times 100 \mathrm{~mm}$ with $\mathrm{w} / \mathrm{c}$ ratio of 0.3 . After water curing for $7,14,28$, and 90 days, the specimens were subjected to compressive strength tests using an AIMIL compression testing machine (Aimil Ltd., New Delhi, India) of $2000 \mathrm{kN}$ capacity at a rate of loading of $140 \mathrm{kN} / \mathrm{min}$. The tests were carried out on triplicate specimens and the average compressive strength values were recorded.

The splitting tensile test was carried out in concrete cylinders of size $100 \mathrm{~mm}$ diameter and $200 \mathrm{~mm}$ height as per ASTM C496 [34]. After water curing for 28 days, the concrete cylinders were subjected to splitting tensile test by using a universal testing machine. Tests were carried out on triplicate specimens and the average splitting tensile strength values were recorded.

The durability of concretes was determined by the rapid chloride ion penetration test (RCPT) as per ASTM C1202 [35]. Concrete discs with $85 \mathrm{~mm}$ diameter and $50 \mathrm{~mm}$ thickness were cast and cured for 28 days. After curing, the concrete specimens were subjected to RCPT test by impressing $60 \mathrm{~V}$. Two halves of the specimen was sealed with PVC container of diameter $90 \mathrm{~mm}$. One side of the container is filled with $3 \% \mathrm{NaCl}$ solution (that side of the cell will be connected to the negative terminal of the power supply), the other side is filled with $0.3 \mathrm{~N} \mathrm{NaOH}$ solution (which will be connected to the positive terminal of the power supply). Current is measured every $30 \mathrm{~min}$ for up to $6 \mathrm{~h}$. Chloride contamination and temperature at every $30 \mathrm{~min}$ was also monitored. From the results using current and time, chloride permeability was calculated in terms of Coulombs at the end of $6 \mathrm{~h}$.

The morphology of concretes after curing for 90 days was determined by a JSM 820 scanning electron microscope (SEM, JEOL, Tokyo, Japan) with an acceleration voltage of 15-20 keV. 


\section{Results and Discussion}

\subsection{Chemical Compositions and Physical Properties of SF and RHA}

The oxide analyses for cement, SF, and RHA samples are listed in Table 2. Table 2 shows a significantly high content of amorphous $\mathrm{SiO}_{2}$ in $\mathrm{SF}$, with small amounts of iron, magnesium, alumina, calcium, and alkali oxides. RHA exhibits a lower $\mathrm{SiO}_{2}$ amount (82.9\%) than SF (94\%). XRD analysis (Figure 1) showed that SF and RHA possess similar mineralogical spectra, and their silica phases corresponding to $22.5^{\circ}(2 \theta)$ were mostly in amorphous form, which are both active.

Table 2. Chemical compositions of cement, SF, and RHA.

\begin{tabular}{cccc}
\hline Chemical Composition (\%) & Cement & SF & RHA \\
\hline $\mathrm{SiO}_{2}$ & 22.52 & 94 & 82.9 \\
$\mathrm{Al}_{2} \mathrm{O}_{3}$ & 5.80 & 0.21 & 0.29 \\
$\mathrm{Fe}_{2} \mathrm{O}_{3}$ & 3.52 & 0.09 & 1.83 \\
$\mathrm{SO}_{3}$ & 2.54 & - & 1.34 \\
$\mathrm{CaO}$ & 62.08 & 0.12 & 2.29 \\
$\mathrm{MgO}$ & 1.55 & 0.33 & 0.93 \\
$\mathrm{Na}$ & 0.05 & - & 0.06 \\
$\mathrm{~K}_{2} \mathrm{O}$ & 0.56 & 0.38 & 6.82 \\
L.O.I. & 0.94 & 1.2 & 1.5 \\
\hline
\end{tabular}

Note: L.O.I.: Loss on ignition.
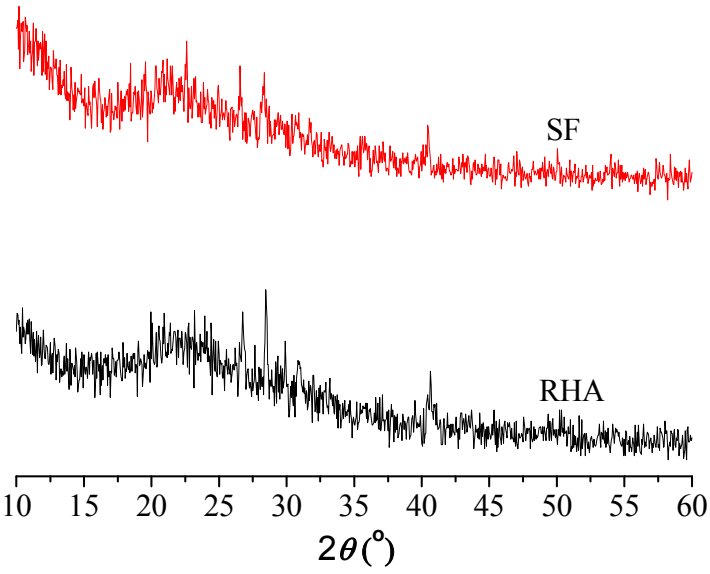

Figure 1. XRD spectrum of SF and RHA.

The physical properties of cement, SF, and RHA are recorded in Table 3. It is seen that specific gravity of SF and RHA are less than that of cement. The specific gravity of RHA increase with the increase of grinding duration. The mean particle size of RHA decreases from 9.49 to $5.69 \mu \mathrm{m}$ with a grinding duration from 5 to $30 \mathrm{~min}$ and, accordingly, the specific surface area rises from 19.4 to $23.6 \mathrm{~m}^{2} / \mathrm{g}$. The mean particle size of FRHA $\left(\mathrm{d}_{50}=5.69 \mu \mathrm{m}\right)$ is larger than that of SF $\left(d_{50}=5.11 \mu \mathrm{m}\right)$. However, FRHA presents a higher specific surface area compared to $\mathrm{SF}$, attributed to its very porous structure of each single particle. This analysis is complemented with the SEM images in Figure 2. As shown in Figure 2a, spherical particles of silica fume present a smooth, dense surface. The FRHA powder surface is very porous as seen in Figure $2 b$. The size of these surface pores on FRHA particles is less than $50 \mathrm{~nm}$. These nano-scale pores greatly contribute to high specific surface area and high pozzolanic reactivity of RHA. 
Table 3. Physical properties of cement, SF, CRHA, and FRHA.

\begin{tabular}{ccccc}
\hline Physical Properties & Cement & SF & CRHA & FRHA \\
\hline Specific gravity & 3.12 & 2.8 & 2.32 & 2.61 \\
Surface area $\left(\mathrm{m}^{2} / \mathrm{g}\right)$ & $0.34($ Blain $)$ & $21.08(\mathrm{BET})$ & $19.4(\mathrm{BET})$ & $23.6(\mathrm{BET})$ \\
Mean particle size, $\mathrm{d}_{50}(\mu \mathrm{m})$ & 12 & 5.11 & 9.49 & 5.69 \\
\hline
\end{tabular}

Note: CRHA: RHA with 5 min grinding; and FRHA: RHA with 30 min grinding.

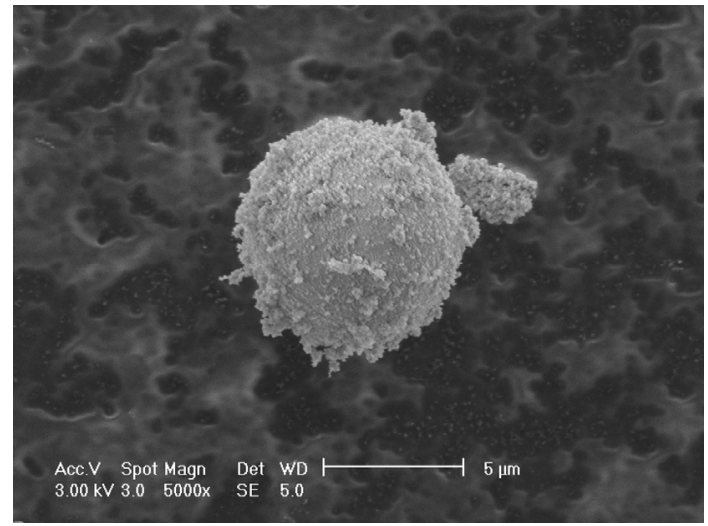

(a)

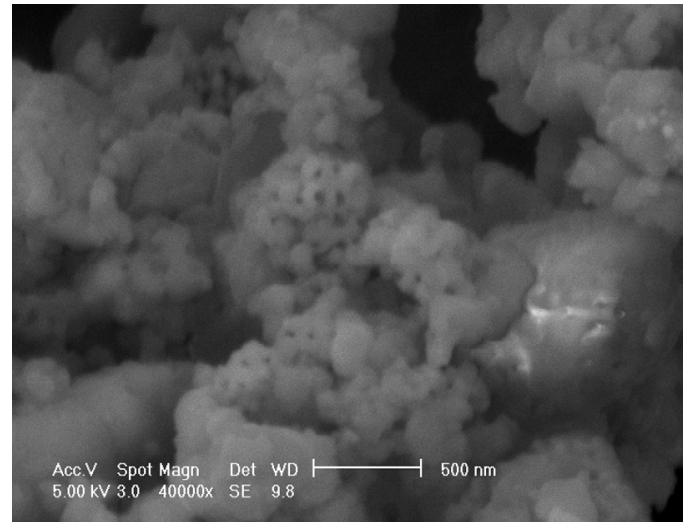

(b)

Figure 2. SEM images of SF and ground RHA: (a) SF; (b) FRHA (30 min grinding).

\subsection{Compressive Strength of Blended Cement Pastes}

The compressive strength results of cement paste and pastes with incorporation of $10 \%$ cement replaced by CRHA, FRHA, and SF is shown in Figure 3. The SF blended paste shows the highest strength value $(82.70 \mathrm{MPa})$ among all the pastes at the age of 90 days, which is $17 \%$ higher than the control paste. This is related to the high content and high surface area of pure glassy silica in $\mathrm{SF}$, which exhibits excellent pozzolanic reactivity and the well packing effect of SF particles in the cement composite.

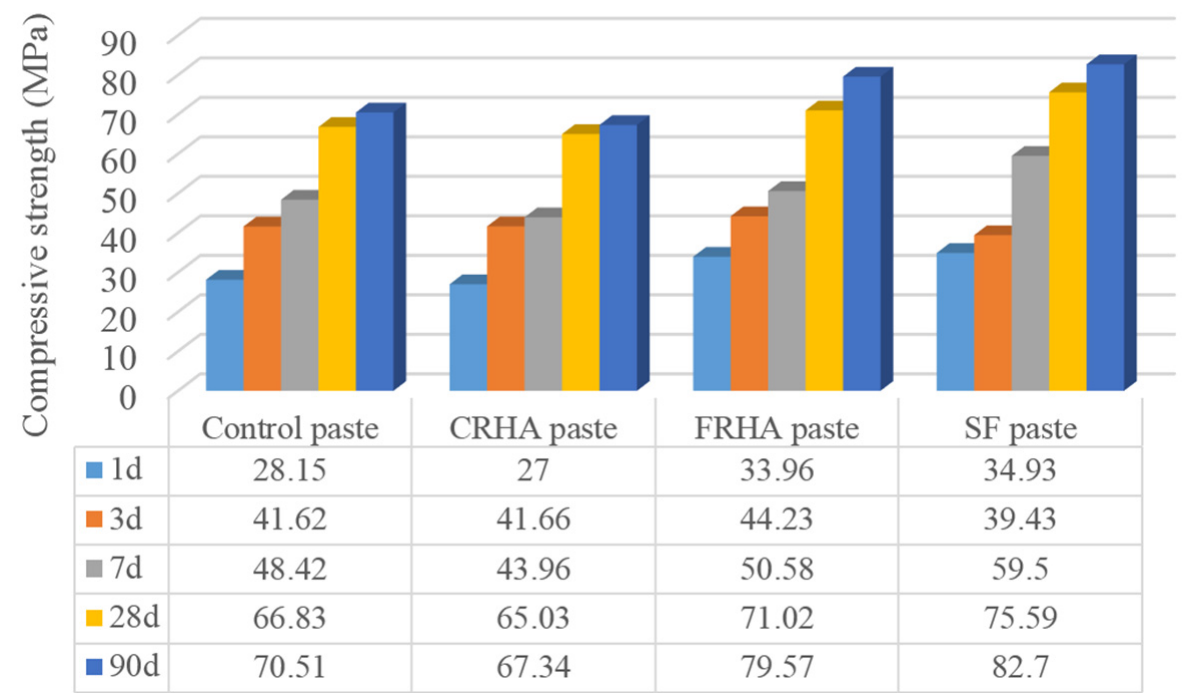

Figure 3. Compressive strength of pastes. 
It can be seen that the paste incorporating CRHA shows the lowest compressive strength at all the testing curing ages, which may be due to the larger particle size and lower surface area of coarse RHA particles. Strength of paste incorporating RHA increases with increase of grinding duration from 5 to $30 \mathrm{~min}$. The FRHA paste presents a $79.59 \mathrm{MPa}$ compressive strength at the age of 90 days, which is $12.8 \%$ higher than that of the control paste and exhibits comparable strength value with SF paste $(82.70 \mathrm{Mpa})$. Results show that the addition of finely ground RHA to paste gives rise to an increase of the compressive strength compared to the control concrete, due to the increasing specific surface area and pozzolanic reactivity of RHA.

\subsection{Hydration Process of Blended Cement Pastes at 1, 7, and 28 Days}

The thermogravimetric weight losses of control, SF paste and FRHA paste samples at 1, 7, and 28 days were plotted in Figure $4 \mathrm{a}-\mathrm{c}$. It is seen that curves of all pastes show three rapid weight losses. The first weight loss, located between 110 and $300{ }^{\circ} \mathrm{C}$, is mainly due to dehydration of C-S-H. The second major weight loss, observed at $450-550{ }^{\circ} \mathrm{C}$, corresponds to the dehydroxylation of portlandite, another hydration product. The third weight loss appears at $750{ }^{\circ} \mathrm{C}$, which corresponds to the decarbonation of calcium carbonate deriving from the cement clinker [33]. The quantitative analysis for the first weight loss and the second weight loss can be used as an indicator of the hydration reaction degree of the cement composite matrix.

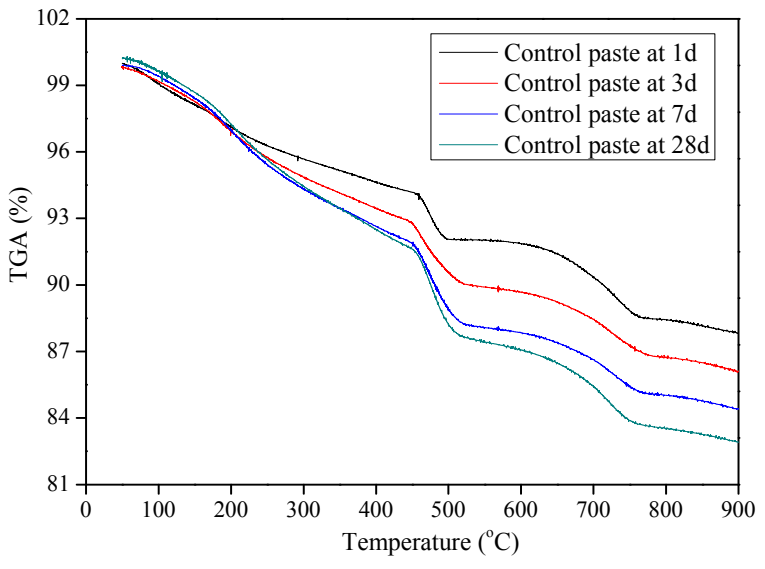

(a)

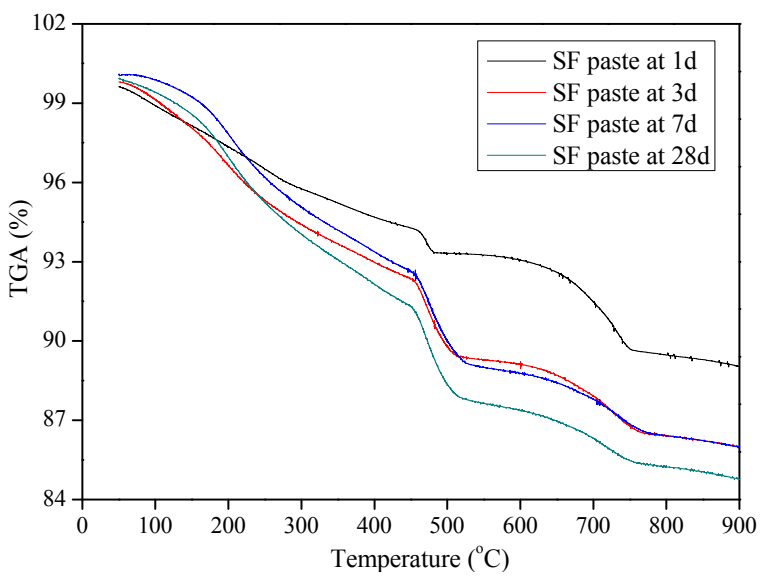

(b)

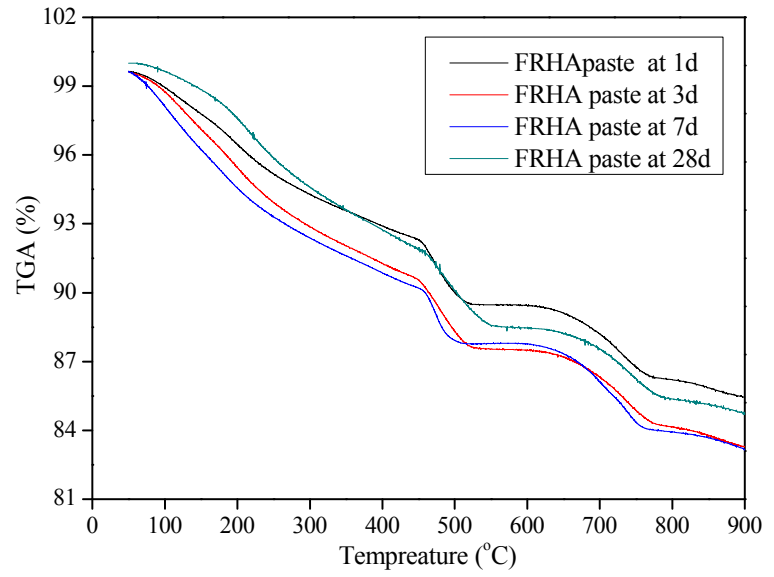

(c)

Figure 4. (a) TGA curve of control paste at 1, 3, 7, and 28 days; (b) TGA curve of SF paste at 1, 3, 7, and 28 days; and (c) TGA curve of FRHA paste at $1,3,7$, and 28 days. 
The weight losses of paste specimens are summarized in Table 4 . These values are calculated from the testing data in Figure 4. It is observed that the weight loss of the control paste is increased from $40.57 \%$ to $44.70 \%$ with an increase in the curing age from 1 to 7 days. The weight loss of the control paste is $44.69 \%$ at the age of 28 days, indicating the weight loss for the control paste remains even at the curing age from 7 to 28 days. The weight loss of SF at the first stage is increased from $46.59 \%$ to $51.04 \%$ at the curing age from 1 to 28 days. For the FRHA paste, the weight loss caused by the dehydration reaction at the first stage is increased from $44.21 \%$ to $49.90 \%$ with increase in curing age from 1 to 28 days. Comparing the dehydration weight losses of all the paste samples at the age of 28 days, the SF presents the highest value compared to the control paste and the FRHA paste. The weight loss of dehydration of the FRHA paste follows the SF paste by second and shows 5.12\% higher than that of the control paste. Results also indicate that the rate of hydration of FRHA paste is initially lower than that of SF paste but higher than the control paste. Therefore, SF particles can contribute to the high early age strength and the FRHA increases the long-term strength, although this strength is lower than SF blended paste at all ages, which is consistent with previous reports [20].

Table 4. Weight losses of pastes at the ages of 1,3, 7 and 28 days.

\begin{tabular}{ccccccc}
\hline \multirow{2}{*}{ Paste Specimen } & \multicolumn{3}{c}{ Weight Loss (\%) } & \multicolumn{3}{c}{$\begin{array}{c}\text { Weight Loss with Respect to the } \\
\text { Total Weight Loss (\%) }\end{array}$} \\
\cline { 2 - 7 } & Stage 1 & Stage 2 & Stage 3 & Stage 1 & Stage 2 & Stage 3 \\
\hline Control-1d & 3.16 & 2.16 & 2.47 & 40.57 & 27.73 & 31.70 \\
Control-3d & 4.15 & 2.88 & 2.39 & 44.09 & 30.53 & 25.37 \\
Control-7d & 4.96 & 3.88 & 2.26 & 44.70 & 34.95 & 20.35 \\
Control-28d & 5.21 & 3.95 & 2.50 & 44.69 & 33.85 & 21.46 \\
SFP-1d & 3.02 & 1.02 & 2.44 & 46.59 & 15.73 & 37.68 \\
SFP-3d & 4.62 & 2.97 & 1.93 & 48.51 & 31.24 & 20.25 \\
SFP-7d & 5.13 & 3.13 & 1.92 & 50.40 & 30.73 & 18.87 \\
SFP-28d & 5.33 & 3.24 & 1.87 & 51.04 & 31.04 & 17.92 \\
FRHAP-1d & 4.42 & 2.74 & 2.84 & 44.21 & 27.43 & 28.36 \\
FRHAP-3d & 5.55 & 3.00 & 3.04 & 47.89 & 25.89 & 26.22 \\
FRHAP-7d & 5.33 & 2.94 & 2.42 & 49.85 & 27.49 & 22.66 \\
FRHAP-28d & 5.51 & 3.17 & 2.37 & 49.90 & 28.67 & 21.43 \\
\hline
\end{tabular}

Note: SFP: paste incorporating SF; and FRHAP: paste incorporating 30 min grinding RHA.

As for the second weight loss stage corresponding to dehydroxylation, the control, the SF paste and the FRHA paste shows 33.85\%, 28.67\%, and 31.04\%, respectively, at the age of 28 days. The SF paste and the FRHA paste show lower weight loss percentage in dehydroxylation reaction corresponding to $\mathrm{Ca}(\mathrm{OH})_{2}$ dehydroxylation compared to the control paste, which also indicates the excellent pozzolanic activity of SF and FRHA.

\subsection{Workability of Concretes}

The slump testing results of fresh concrete mixtures are listed in Table 5. It is observed that the slump of the control concrete is $85 \mathrm{~mm}$. SF addition decreases the slump values of fresh concrete mixtures with increase in 5\% to $30 \%$ cement replacement. The values of the SF mixtures vary between 95 and $25 \mathrm{~mm}$ with an increase in the dosage of SF. With the addition of 5\% and 10\% cement replaced by FRHA, the slump of the concrete mixtures is $125 \mathrm{~mm}$ and $100 \mathrm{~mm}$, and are higher than that of the control concrete mixtures, which may be related to the well packing of the cementitious system. However, the slump value decreases with the increase of FRHA dosage in the mixtures. The slump value is significantly reduced to $15 \mathrm{~mm}$ with $25 \%$ and $30 \%$ cement replaced by FRHA. There are significant declines of slump with increase of SF and FRHA addition in the mixtures with 5\% to $30 \%$ cement replacement ratio. This may be due to that addition of SF and FRHA aggravates narrow particle size distributions of the concrete mixtures and, hence, resulting in a higher water demand. 
Table 5. Slump, compressive strength, and splitting tensile strength of concretes.

\begin{tabular}{ccccccc}
\hline \multirow{2}{*}{ Concrete ID } & $\begin{array}{c}\text { Slump } \\
\text { (mm) }\end{array}$ & \multicolumn{3}{c}{ Compressive Strength (MPa) } & \multicolumn{2}{c}{ Splitting Tensile Strength (MPa) } \\
\cline { 3 - 6 } & & $\mathbf{7 d}$ & $\mathbf{1 4 d}$ & $\mathbf{2 8 d}$ & $\mathbf{9 0 d}$ & $\mathbf{2 8 d}$ \\
\hline Control & 85 & 75.06 & 83.60 & 86.81 & 92.52 & 58.93 \\
SF5\%C & 95 & 83.12 & 86.94 & 91.33 & 99.56 & 62.78 \\
SF10\%C & 55 & 93.11 & 98.54 & 105.82 & 109.69 & 69.87 \\
SF15\%C & 45 & 98.33 & 100.50 & 101.62 & 103.22 & 65.75 \\
SF20\%C & 35 & 93.86 & 98.13 & 101.48 & 102.72 & 65.43 \\
SF25\%C & 30 & 93.30 & 97.62 & 100.25 & 101.46 & 64.63 \\
SF30\%C & 25 & 91.15 & 94.23 & 95.88 & 98.31 & 62.62 \\
FRHA5\%C & 125 & 78.93 & 89.04 & 93.62 & 99.51 & 63.39 \\
FRHA10\%C & 100 & 97.63 & 99.97 & 101.97 & 106.88 & 65.09 \\
FRHA15\%C & 80 & 83.72 & 88.35 & 97.00 & 102.19 & 58.53 \\
FRHA20\%C & 48 & 82.02 & 85.18 & 88.67 & 91.88 & 56.07 \\
FRHA25\%C & 15 & 79.25 & 80.13 & 82.13 & 88.03 & 52.18 \\
FRHA30\%C & 15 & 74.85 & 78.95 & 80.90 & 81.91 & \\
\hline
\end{tabular}

\subsection{Compressive Strength of Concretes}

The compressive strength results of concrete specimens are shown in Table 5. It is seen that the compressive strength of the control concrete is 86.81 and $92.52 \mathrm{MPa}$ at 28 and 90 days, respectively.

For series of SF concretes, the 28-day compressive strength of $5 \% \mathrm{SF}, 10 \% \mathrm{SF}$, and $15 \% \mathrm{SF}$ concrete is $91.33,105.82$, and $101.62 \mathrm{MPa}$, which is $105 \%, 122 \%$, and $117 \%$ of the control concrete, respectively. However, further increasing in cement replacement ratio of SF, the compressive strength of concrete is reduced. At 90 days, the compressive strength of $5 \% \mathrm{SF}, 10 \% \mathrm{SF}$, and $15 \% \mathrm{SF}$ concretes is $98.56,109.69$, and 103.22 MPa, respectively. The highest compressive strength value appears on the $10 \% \mathrm{SF}$ concrete, which was $119 \%$ of the control concrete at the age of 90 days.

Compressive strength of 5\%FRHA, 10\%FRHA, and 15\%FRHA concretes at 28 days is 93.62, 101.97, and $97 \mathrm{MPa}$ or $108 \%, 117 \%$, and $112 \%$ of the control concrete, respectively. At the later age, their strengths are slightly increased, and, 90-day compressive strength of these concretes is 99.51, 106.88, and $102.19 \mathrm{MPa}$ or $108 \%, 116 \%$, and $110 \%$ of the control concrete, respectively. It is observed that the compressive strength of $20 \%$ FRHA concrete at 90 days is slightly lower than that of control concrete. Again, increasing the cement replacement ratio of FRHA to 25\% and 30\% decreases the strength of concrete. Therefore, the optimal ratio of cement replaced by FRHA is $10 \%$. However, the normalized compressive strength of all FRHA concretes increased with the ages. This suggests that the contribution of compressive strength gain is due to the pozzolanic reaction of FRHA with $\mathrm{Ca}(\mathrm{OH})_{2}$ released from hydration of cement.

Comparing the compressive strength of the SF concrete and the FRHA concrete at different ages, the incorporation of up to $30 \%$ of SF or $15 \%$ of FRHA does not adversely affect the strength of cement concrete. A further increase in the cement replacement ratios to 20\% FRHA and 25\% SF, however, decreases the strength of concrete. For the same replacement ratio of $10 \%$, the strengths of SF and FRHA concretes were similar to each other and significantly higher than that of control concrete. This suggests an excellent pozzolanic reactivity and filler effect of SF and FRHA which makes concrete denser. In addition, the strengths of the SF concretes are higher than those of the FRHA concretes with the same cement replacement ratio, indicating that $\mathrm{SF}$ is more reactive than FRHA. This is because the RHA used in this study contains certain amount of unburnt carbon particles, which impairs the purity of the amorphous $\mathrm{SiO}_{2}$ and, hence, compromising its pozzolanic activity. To overcome this, satisfactory treatment conditions such as acid leaching of rice husks prior to combustion or mechanical ultrafine grinding of RHA may minimize the effect of the residual carbon or presence of the crystalline compounds. 


\subsection{Splitting Tensile Strength of Concretes}

The splitting tensile strength results of SF and FRHA concrete at the curing age of 28 days are shown in Table 5. It is seen that, all the SF concretes exhibit higher splitting tensile strength values than the FRHA concrete at the same cement replacement level. For the FRHA concrete series, at $5 \%$ and $10 \%$ cement replacement level, the splitting tensile strength of the concrete increases to $63.39 \mathrm{MPa}$ and $68.09 \mathrm{MPa}$, which is $7.6 \%$ and $15.5 \%$ higher than that of control concrete, respectively; while beyond $10 \%$ cement replacement level by FRHA, the decrease in splitting tensile strength is observed.

\subsection{Rapid Chloride Permeability of Concretes}

The limit values along with classification ratings of chloride penetrability of concrete in accordance with ASTM C1202 [35] are shown at Table 6. The changes of total charge passed of concrete specimens at the age of 28 days are shown at Table 7 . The test results in Table 7 have been evaluated according to limit values according to Table 6 .

Table 6. Limit values according to ASTM C1202 [35].

\begin{tabular}{cc}
\hline Charge Passed (Coulombs) & Chloride Permeability \\
\hline$>4000$ & High \\
$2000-4000$ & Moderate \\
$1000-2000$ & Low \\
$100-1000$ & Very low \\
$<100$ & Negligible \\
\hline
\end{tabular}

Table 7. Coulomb charges of concretes at 28 days.

\begin{tabular}{ccc}
\hline Concrete Specimens & $\begin{array}{c}\text { Coulomb Charges of } \\
\text { Concretes (C) }\end{array}$ & $\begin{array}{c}\text { Evaluation of Concrete } \\
\text { According to ASTM C1202 [35] }\end{array}$ \\
\hline Control & 528.67 & Very low \\
SF5\%C & 493.28 & Very low \\
SF10\%C & 212.44 & Very low \\
SF15\%C & 198.36 & Very low \\
SF20\%C & 188.63 & Very low \\
SF25\%C & 273.28 & Very low \\
SF30\%C & 292.6 & Very low \\
FRHA5\%C & 478.69 & Very low \\
FRHA10\%C & 327.67 & Very low \\
FRHA15\%C & 393.2 & Very low \\
FRHA20\%C & 567.44 & Very low \\
FRHA25\%C & 1023.58 & Low \\
FRHA30\%C & 2088.63 & Moderate \\
\hline
\end{tabular}

It is seen that the chloride permeability of the control and the SF concretes are evaluated as "very low". It is found that chloride permeability of FRHA series is "very low" when FRHA is used at 5\% to $20 \%$ cement replacement ratio. When FRHA is used at $25 \%$ and $30 \%$ ratios, chloride permeability of concrete rises to "low" and "moderate" level, respectively. It is also found that comparing to the improvement of compressive strength of FRHA blended concretes with optimum replacement levels less than $15 \%$ by weight of cement, the chloride permeability of FRHA concretes show improvement of durability with higher optimum replacement dosages up to $20 \%$, which is also in line with previous studies [36,37].

\subsection{SEM Morphology of Concretes}

The SEM morphologies of control, SF, and FRHA concrete are shown in Figures 5-7. The SEM images of the control concrete are shown in Figure 5a,b. The image in Figure 5a shows a large aggregate 
on the left side covering the area in the image almost diagonally. The surface is wavy and contains crests and troughs, or concave and convex areas. The adjacent areas are covered loosely porous C-S-H gel. Further magnifying the C-S-H gel area at higher magnifications of $\times 8131$ as shown in Figure $5 b$, it is seen the C-S-H gel area appears to be dense along with some pores with length of 1 to above $5 \mu \mathrm{m}$. A slice of flake-like calcium hydroxide and needle-like crystals are found to cover the surface of C-S-H gel matrix.

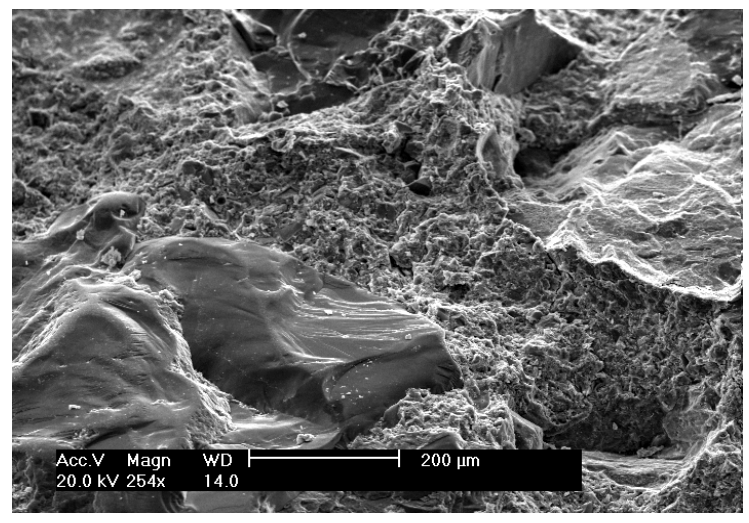

(a)

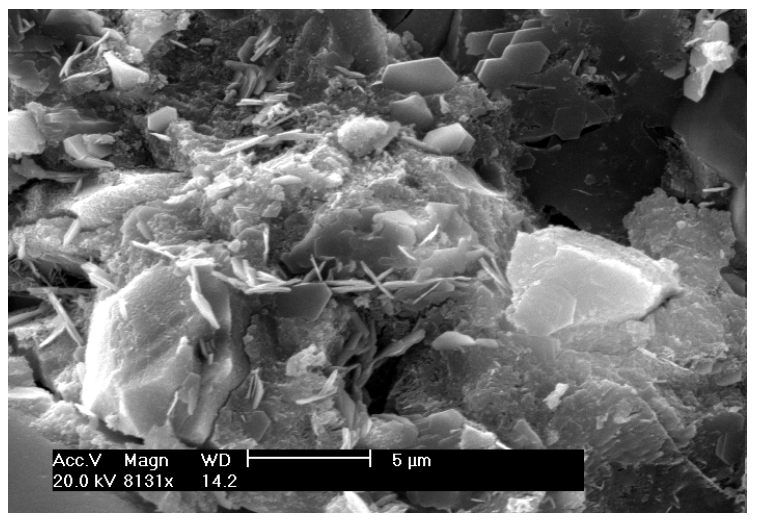

(b)

Figure 5. SEM of control concrete: (a) with magnification of $\times 254$; (b) with magnification of $\times 8131$.

Figure 6a presents the morphology of the SF concrete at the age of 28 days. The hydrated cement matrix area at magnification of $\times 10030$ as shown in Figure $6 \mathrm{~b}$ presents a tightly-packed hydrated C-S-H gel only alone with a few pores with a length of 1 to $3 \mu \mathrm{m}$, and there is no sign of calcium hydroxide and needle-like crystals. The dense hydrated area of SF concrete indicates a very compact texture.

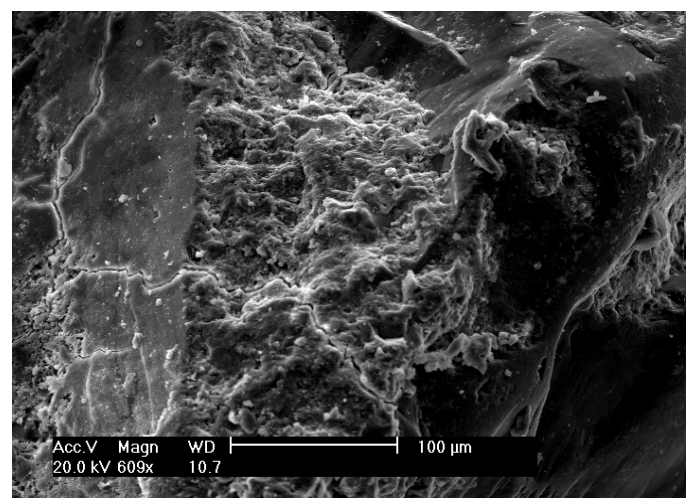

(a)

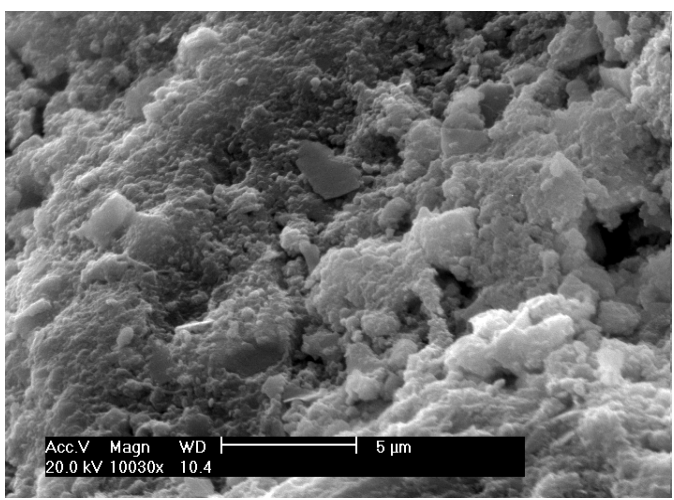

(b)

Figure 6. SEM of SF concrete: (a) with magnification of $\times 609$; (b) with magnification of $\times 10030$.

Figure 7a shows the morphology of fractured surfaces of FRHA concrete curing at room temperature for 28 days. It is seen the cement paste penetrates into the aggregate and forms a stronger bond. Further magnifying the cement hydrate area as shown in Figure 7b, two distinct phases can be clearly seen: the C-S-H gel and the needle-like crystals. The flake-shaped calcium hydroxide crystalline phase does not appear on the glassy phase surface of SF and FRHA concrete, indicating reactive silica in FRHA and SF can enhance and accelerate secondary hydration reaction of $\mathrm{Ca}(\mathrm{OH})_{2}$ in cement matrix. However, the needle-like crystalline phase presented in FRHA is possibly due to minor crystallization of the aluminosilicate species, which, to some extent, impairs the strength gain of cement composite. These morphological differences may also be responsible for compressive strength differences among the concrete specimens. 


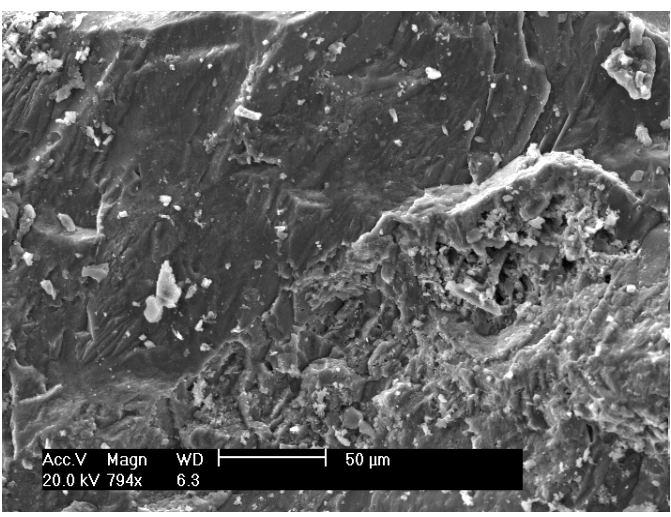

(a)

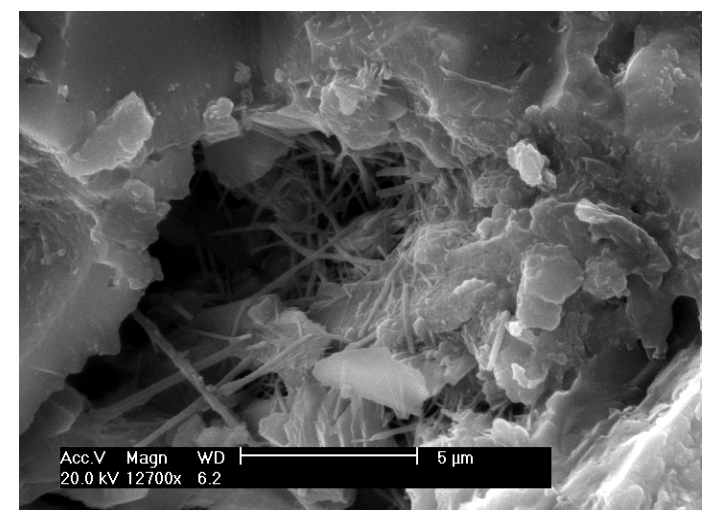

(b)

Figure 7. SEM of FRHA concrete: (a) with magnification of $\times 794 ;(\mathbf{b})$ with magnification of $\times 12700$.

\section{Conclusions}

The following conclusions can be drawn from the results of this study:

1. Although RHA used in this study possesses lower $\mathrm{SiO}_{2}$ content and larger particle size compared to SF, the finely-ground RHA presents a higher surface area due to the nano-scale pores on each single RHA particle. These nano-scale pores with size less than $50 \mathrm{~nm}$ greatly contribute to the high surface area and high pozzolanic reactivity of RHA.

2. According to the compressive strength results of pastes, at $10 \%$ cement replacement ratio, the $\mathrm{SF}$ blended paste shows the highest compressive strength value among all the paste samples at the age of 90 days, which is $17 \%$ higher than control paste. As for the series of RHA paste, results show that the pozzolanic reactivity of RHA increases with the increase of grinding fineness. FRHA paste presents $12.8 \%$ higher than that of the control paste and exhibits comparable strength value with SF paste. The TGA analysis results of paste reveal that the FRHA shows a high pozzolanic reactivity and can be comparable with SF.

3. The concrete tests show that although the optimal level of SF and FRHA content were achieved with $10 \%$ cement replacement by mass, test results show a significant reduction in slump for the blended fresh mixtures. It is found that cement could be advantageously replaced by SF and RHA up to maximum limit of $30 \%$ and $15 \%$, respectively. At the same mix, SF concrete specimens present higher compressive and splitting tensile strength compared to the FRHA concrete specimens, indicating SF is more reactive than FRHA. This may be attributed to the limitation of burning and grinding treatment condition of RHA in this study. However, superior highly-reactive RHA could be expected if satisfactory pretreatment conditions such as acid leaching of rice husks or mechanical ultrafine grinding of RHA are utilized, which may minimize the effect of the residual carbon or presence of the crystalline compounds in RHA.

4. The chloride permeability of SF blended concretes is "very low" rating when SF content is up to $30 \%$. The "very low" rating of FRHA concretes appears at concrete with FRHA addition within the $20 \%$ cement replacement level.

5. The SEM morphology analyses manifest that cement paste penetrates into the aggregate and forms a strong interfacial bond, and there is no sign of calcium hydroxide in SF and FRHA concrete, indicating reactive silica in FRHA and SF can enhance and accelerate the secondary hydration reaction of $\mathrm{Ca}(\mathrm{OH})_{2}$ in cement matrix. However, a slice of needle-like crystalline phase presented in FRHA is possibly due to minor crystallization of the aluminosilicate species, which, to some extent, impairs the strength gain of RHA blended cement composite. These morphological differences may also be responsible for compressive strength differences among the concrete specimens. 
Based on this experimental study, it is found that finely ground RHA exhibits comparable pozzolanic reactivity with SF and can contribute to various improvements in the performance of cementitious system. Considering SF is not economically available even in developed countries, utilization of RHA in cementitious materials can not only reduce materials costs, but also lessen the environmental burdens associated with the current open field burning of the husk in rice-producing countries. Thus, broad application prospect of RHA instead of SF in cementitious materials could be expected due to the advantages of cost savings, and environmental benefits related to the disposal of waste materials and to reduced carbon dioxide emissions.

Acknowledgments: The authors greatly acknowledge the financial supports from the National Natural Science Foundation of China (Grant No. 51408363, 51378312 and 51478207), China Postdoctoral Science Foundation (Grant No. 2014M562210), Shenzhen Science and Technology Project (JCYJ20150626090329072) and Cooperation Foundation of Industry, Education and Academy from Education Department of Guangdong Province Government (Grant No. 2012B091000149).

Author Contributions: Weiting Xu conceived the experiments and wrote the paper; Lo Tommy Yiu, Weilun Wang, Dong Ouyang and Feng Xing contributed reagents, materials and analysis tools.

Conflicts of Interest: The authors declare no conflict of interest.

\section{References}

1. Lawania, K.; Sarker, P.; Biswas, W. Global warming implications of the use of by-products and recycled materials in western Australia's housing sector. Materials 2015, 8, 6909-6925. [CrossRef]

2. Ludwig, H.M.; Zhang, W.S. Research review of cement clinker chemistry. Cem. Concr. Res. 2015, 78, 24-37. [CrossRef]

3. Rajabipour, F.; Maraghechi, H.; Fischer, G. Investigating the alkali silica reaction of recycled glass aggregates in concrete materials. J. Mater. Civil Eng. 2010, 22, 1201-1208. [CrossRef]

4. Mirzahosseini, M.R.; Riding, K.A. Influence of different particle sizes on reactivity of finely ground glass as new supplementary cementitious material (SCM). Cem. Concr. Compos. 2015, 56, 95-105. [CrossRef]

5. Liu, S.H.; Xie, G.S.; Wang, S. Effect of curing temperature on hydration properties of waste glass powder in cement-based materials. J. Therm. Anal. Calorim. 2015, 119, 47-55. [CrossRef]

6. Mirzahosseini, M.R.; Riding, K.A. Influence of curing temperature and glass type on the pozzolanic reactivity of glass powder. Cem. Concr. Res. 2014, 58, 103-111. [CrossRef]

7. Mirzahosseini, M.; Riding, K. Effect of combined glass particles on hydration in cementitious systems. J. Mater. Civil Eng. 2015, 27, 401-419. [CrossRef]

8. Taylor, H.F.W. Cement Chemistry, 2nd ed.; Thomas Telford: London, UK, 1997.

9. Achary, P.K.; Patro, S.K. Effect of lime and ferrochrome ash (FA) as partial replacement of cement on strength, ultrasonic pulse velocity and permeability of concrete. Constr. Build. Mater. 2015, 94, 448-457. [CrossRef]

10. Mermerdaş, K.; Gesoğlu, M.; Güneyisi, E.; Özturan, T. Strength development of concretes incorporated with metakaolin and different types of calcined kaolins. Constr. Build. Mater. 2012, 37, 766-774. [CrossRef]

11. Isaia, G.C.; Gastaldini, A.L.G.; Moraes, R. Physical and pozzolanic action of mineral additions on the mechanical strength of high-performance concrete. Cem. Concr. Compos. 2003, 25, 69-76. [CrossRef]

12. Siddique, R.; Bennacer, R. Use of iron and steel industry by-product (GGBS) in cement paste and mortar. Resour. Conserv. Recy. 2012, 69, 29-34. [CrossRef]

13. Cordeiro, G.C.; Filho, R.D.T.; Tavares, L.M.; Fairbairn, E.M.R.; Hempel, S. Influence of particle size and specific surface area on the pozzolanic activity of residual rice husk ash. Cem. Concr. Compos. 2011, 33, 529-534. [CrossRef]

14. Kar, A.; Ray, I.; Unnikrishnan, A.; Davalos, J.F. Estimation of C-S-H and calcium hydroxide for cement pastes containing slag and silica fume. Constr. Build. Mater. 2012, 30, 505-515. [CrossRef]

15. Van, V.T.A.; Rößler, C.; Bui, D.D.; Ludwig, H.M. Mesoporous structure and pozzolanic reactivity of rice husk ash in cementitious system. Constr. Build. Mater. 2013, 43, 208-216. [CrossRef]

16. Siddique, R. Utilization of silica fume in concrete: Review of hardened properties. Resour. Conser. Recy. 2011, 55, 923-932. [CrossRef] 
17. Khayat, K.H.; Aitcin, P.C. Silica fume: A unique supplementary cementitious material. In Mineral Admixtures in Cement and Concrete; Ghosh, S.N., Ed.; ABI Books Private Limited: New Delhi, India, 1993; Volumn 4, pp. 227-265.

18. Almusallam, A.A.; Beshr, H.; Maslehuddin, M.; Al-Amoudi, O.S.B. Effect of silica fume on the mechanical properties of low quality coarse aggregate concrete. Cem. Concr. Compos. 2004, 26, 891-900. [CrossRef]

19. Behnood, A.; Ziari, H. Effects of silica fume addition and water to cement ratio on the properties of high-strength concrete after exposure to high temperatures. Cem. Concr. Compos. 2008, 30, 2106-2112. [CrossRef]

20. Jalal, M.; Pouladkhan, A.; Harandi, O.F.; Jafari, D. Comparative study on effects of Class F fly ash, nano silica and silica fume on properties of high performance self compacting concrete. Constr. Build. Mater. 2015, 94, 90-104. [CrossRef]

21. Hooton, R.D. Influence of silica fume replacement of cement on physical properties and resistance to sulfate attack freezing and thawing, and alkali-silica reactivity. ACI Mater. J. 1993, 90, 143-152.

22. Mehta, P.K. Rice Husk Ash-A Unique Supplementary Cementing Material. In Proceedings of the International Symposium on Advances in Concrete Technology, Concord, NH, USA, $24-29$ July 1994; Malhotra, V.M., Ed.; CANMET: Concord, NH, USA, 1994; pp. 419-443.

23. Liou, T.H. Preparation and characterization of nano-structured silica from rice husk. Mater. Sci. Eng. 2004, 313, 313-323. [CrossRef]

24. James, J.; Subba, R.M. Reactivity of rice husk ash. Cem. Concr. Res. 1986, 16, 296-302. [CrossRef]

25. Rukzon, S.; Chindaprasirt, P.; Mahachai, R. Effect of grinding on chemical and physical properties of rice husk ash. Int. J. Miner. Metall. Mater. 2009, 16, 242-247. [CrossRef]

26. Ganesan, K.; Rajagopal, K.; Thangavel, K. Rice husk ash blended cement: Assessment of optimal level of replacement for strength and permeability properties of concrete. Constr. Build. Mater. 2008, 22, 1675-1683. [CrossRef]

27. Mehta, P.K. Properties of blended cement made from rice husk ash. ACI Mater. J. 1977, 74, 440-442.

28. Smith, R.G.; Kamwanga, G.A. The Use of Rice Husk for Making a Cementitious Material. In Use of Vegetable Plants and Fibres as Building Materials, Proceedings of the Joint Symposium RILEM/CIB/CCL, Baghdad, Iraq, 7-9 October 1986; pp. 85-94.

29. Zhang, M.H.; Malhotra, V.M. High-performance concrete incorporating rice husk ash as supplementary cementing material. ACI Mater. J. 1996, 93, 629-636.

30. Specification for Portland Cement; BS Standard BS-12; British Standard Institute: London, UK, 1996.

31. Standard Test Method for Specific Gravity of Soil Solids by Gas Pycnometer; ASTM D5550-14; ASTM International: West Conshohocken, PA, USA, 2014.

32. Standard Test Method for Compressive Strength of Hydraulic Cement Mortars; ASTM C109; ASTM International: West Conshohocken, PA, USA, 2013.

33. Lucia, A.R.; Gerard, P.; Etienne, M.; Alain, E. The use of thermal analysis in assessing the effect of temperature on a cement paste. Cem. Concr. Res. 2005, 35, 609-613.

34. Standard Test Method for Splitting Tensile Strength of Cylindrical Concrete Specimens; ASTM Standard C496; ASTM International: West Conshohocken, PA, USA, 2002.

35. Standard Test Method for Electrical Indication of Concrete's Ability to Resist Chloride Ion Penetration; ASTM Standard C1202; ASTM International: West Conshohocken, PA, USA, 2010.

36. Zhang, M.H.; Islam, J. Use of nano-silica to reduce setting time and increase early strength of concretes with high volumes of fly ash or slag. Constr. Build. Mater. 2012, 29, 573-580. [CrossRef]

37. Senff, L.; Hotza, D.; Repette, W.L.; Ferreira, V.M.; Labrincha, J.A. Mortars with nano-SiO 2 and $\mathrm{micro}^{-S i O_{2}}$ investigated by experimental design. Constr. Build. Mater. 2010, 24, 1432-1437. [CrossRef]

(C) 2016 by the authors; licensee MDPI, Basel, Switzerland. This article is an open access article distributed under the terms and conditions of the Creative Commons by Attribution (CC-BY) license (http://creativecommons.org/licenses/by/4.0/). 